\title{
Pain, Fatigue, Nausea, and Vomiting as Predictors of Anxiety in Patients Undergoing Hematopoietic Stem Cell Transplantation: A Cross-sectional Study
}

Nilofar Pasyar

Shiraz University of Medical Sciences

Masoume Rambod ( $\square$ rambodma@yahoo.com )

Shiraz University of Medical Sciences https://orcid.org/0000-0002-7334-9364

Fatemeh Zahedi

Shiraz University of Medical Sciences

Mani Ramzi

Shiraz University of Medical Sciences

\section{Research Article}

Keywords: Anxiety, Pain, Fatigue, Nausea, Vomiting, Hematopoietic stem cell transplantation

Posted Date: November 15th, 2021

DOl: https://doi.org/10.21203/rs.3.rs-984888/v1

License: (a) (i) This work is licensed under a Creative Commons Attribution 4.0 International License. Read Full License 


\section{Abstract}

\section{Purpose}

The present study aimed to determine the predictive roles of pain, fatigue, nausea, and vomiting in anxiety among the patients undergoing Hematopoietic Stem Cell Transplantation (HSCT).

\section{Methods}

The present cross-sectional study was conducted on 200 patients treated by HSCT referred to the centers affiliated to Shiraz University of Medical Sciences, Iran. The data were collected using Spielberger Anxiety Questionnaire, Numerical Pain Scale, Brief Fatigue Inventory, and Rhodes Nausea and Vomiting Index. Then, the data were analyzed using Spearman's test and multiple regression analysis.

Results

The means of state anxiety, trait anxiety, pain, fatigue, and nausea, vomiting and retching were 41.67 (SD $=9.71), 43.78(S D=9.00), 3.79(S D=2.79), 4.23(S D=2.48), 6.31(S D=7.53)$, respectively. The results showed that the participants with higher pain and fatigue scores had higher anxiety levels. The individuals who had more nausea and vomiting had higher anxiety levels, as well. It indicated that fatigue, pain, amount of vomiting, and severity of nausea, vomiting and retching were the predictors of trait anxiety. This study showed the predictor role of pain, fatigue, and severity of retching in state anxiety.

Conclusion

The study findings revealed an association between anxiety and pain, fatigue, nausea, and vomiting among the HSCT patients. The results also showed that fatigue and pain were the predictors of anxiety among the patients. Yet, future studies are recommended to determine the other factors contributing to anxiety among the HSCT patients.

\section{Introduction}

Hematologic malignancies have been defined as the tumors that arise from bone marrow or lymphoid tissue, affect blood, bone marrow, and the lymphatic system, and are directly related to the circulatory system and immune system (1). Chemotherapy, target therapy, and Hematopoietic Stem Cell Transplantation (HSCT) have been commonly used to treat hematologic malignancies (2). Although HSCT has good clinical outcomes (3), the long course of the disease and the unpredictability of the treatment process are among its main challenges (4). HSCT is also an invasive and complex procedure that causes many complications for patients due to the pre-bone marrow preparation regimen, which includes receiving high doses of chemotherapy drugs and whole-body radiation therapy (5). Anxiety is one of the consequences of cancer diagnosis and treatment. It is in fact one of the common psychological complications (6). The prevalence of anxiety has been found to be high in patients with hematologic malignancies treated by HSCT (7). Before transplantation, $30 \%$ of patients experienced 
increased anxiety levels (8). Patients with hematologic malignancies who were transplanted and had COVID-19 were also prone to anxiety and depression (9). Overall, anxiety could have negative effects on cancer patients, including increased complications-related treatment, slow physical recovery, decreased quality of life, and reduced survival rate (10). The risk of COVID-19 infection and discontinuation of cancer treatment could further exacerbate the symptoms of anxiety and depression in cancer patients and have a greater impact on their clinical prognosis (11). Anxiety can also affect the sensation of pain experienced by HSCT patients (12). Pain is the most common and debilitating symptom among HSCT patients (13). Pain can result from the side effects of chemotherapy drugs or acute complications after HSCT (14). Psychological distress, which is an important component of cancer pain, has increased during the COVID-19 crisis due to quarantine and social isolation (15). Besides, anxiety can lead to fatigue in HSCT patients (16). One study found that most HSCT survivors experienced fatigue continuously one year (62.3\%), three years (68\%), and six years (63.8\%) after transplantation (16). It should also be noted that patients' psychological problems before HSCT could affect the severity of their perceived fatigue (17). Moreover, mental fatigue after HSCT could be associated with cognitive dysfunction (18). One of the main causes of anxiety in cancer patients is nausea and vomiting (19). Chemotherapy-induced nausea and vomiting is a global experience among HSCT patients (20). Chemotherapy regimens before HSCT are the most common cause of nausea and vomiting within the first week after transplantation (21). The studies performed amongst patients undergoing HSCT have mainly assessed the physical and psychological complications of treatment, such as anxiety $(7,8)$, pain $(13,22)$, fatigue $(16,23)$, and nausea and vomiting $(21,24)$. However, less attention has been paid to the association between complications following treatment and the predictive role of these complications in the level of anxiety among the patients undergoing HSCT. Therefore, the present study aims to investigate the predictive roles of pain, fatigue, nausea, and vomiting in anxiety among the patients undergoing HSCT.

\section{Methods}

This was a cross-sectional and correlational study. The data were collected in Nemazee Hospital and Motahhari Clinic affiliated to Shiraz University of Medical Sciences from September 2020 to March 2021.

The sample size was based on a pilot study on 10 HSCT patients in which all of the correlation coefficient between state and trait anxiety and pain, fatigue, severity and frequency of nausea, vomiting, and retching and amount of vomiting were $\geq 0.250$. However, the correlation between state anxiety and duration of nausea was 0.227 and had lowest correlation. Therefore, considering $90 \%$ power, $5 \%$ error, $r=$ $0.227 ; 200$ people were determined as the sample size. Finally, this study was performed on 200 patients by convenience sampling. 


$$
\begin{aligned}
& n=\frac{\left(z_{1-\frac{a}{2}+z_{1-\beta}}\right)^{2}}{u_{p}^{2}}+3=200 \\
& u_{p=\frac{1}{2} \ln \frac{1+r}{1-r}} \\
& \mathrm{r}=0.227
\end{aligned}
$$

The inclusion criteria were having undergone HSCT, aging 18 years and above, being oriented to time and place, and being willing to participate in the study. The exclusion criteria were unwillingness to take part in the research and death.

The study data were collected using five questionnaires, including the demographic and clinical information questionnaire, Spielberger State-Trait Anxiety Inventory (STAI), numerical pain scale, Brief Fatigue Inventory (BFI), and Index of Nausea, Vomiting, and Retching.

Demographic and clinical information questionnaire: This form included information, such as age, gender, level of education, marital status, diagnosis, and type of transplant.

STAl: This inventory had 40 questions. The first 20 questions were related to state anxiety and the second 20 questions were related to trait anxiety. The answer to each question was based on a four-point Likert scale, ranging from one to four. Accordingly, the scores were divided into three levels; i.e., mild (20-39), moderate (40-59), and severe (80-60) anxiety. Cronbach's alpha coefficient was reported as 0.92 for state anxiety and 0.90 for trait anxiety. Additionally, the test-retest coefficient was 0.62 for state anxiety and 0.68 for trait anxiety (25). The content validity of the Persian version of STAI was confirmed and its reliability was reported to be $0.81(26)$.

Numerical pain scale: This tool is a standard scale for measuring pain. It is a horizontal ruler divided from 0 to 10. According to this scale, scores $0,1-3,4-6$, and 7-10 indicated pain, mild pain, moderate pain, and severe pain, respectively. The validity of this tool was 0.80 and its reliability was $0.80(27)$. In addition, the reliability of the Persian version of the scale was 0.94 (28).

BFI: This inventory was designed to measure the level of fatigue and consisted of 10 questions. The first question determined the presence or absence of unusual fatigue in the last week using a yes/no question. In questions 2 to 10, the degree of fatigue was examined by different conditions, each being measured on a scale numbered from 0 to 10 . Scores 0 and 10 indicated no fatigue the most severe state of fatigue, respectively. Finally, the patient's fatigue was determined by adding the scores of questions 2 to 10 and dividing it by 9 . Accordingly, scores $0,1-3,4-6$, and 7-10 represented no fatigue, mild fatigue, moderate fatigue, and severe fatigue, respectively. The validity of this questionnaire was found to be 0.76 and its reliability was reported as 0.96 . Overall, this inventory had the highest reliability for measuring fatigue compared to other questionnaires (29). In another study, the validity of this questionnaire was confirmed and its reliability was reported to be 0.90 (30). In the present study, the reliability of BFI was approved by the Cronbach's alpha coefficient of 0.95 . 
Index of Nausea, Vomiting, and Retching: This index aimed at evaluating multiple objective and subjective cases of nausea, vomiting, and retching. This index contained eight questions and was scored based on a five-point Likert scale. The index included three questions about nausea (frequency, severity, and duration of nausea), three questions about vomiting (frequency, severity, and amount of vomiting), and two questions about retching (frequency and severity). These questions could be assigned zero (absence of or minimum symptoms) to four (the worst condition) scores. Thus, the total score of this index could range from 0 to 32, with higher scores representing more severe nausea and vomiting. The validity of this questionnaire was 0.87 and its reliability was 0.98 (31). In another study, the reliability of this index was reported to be 0.88 (32). In the current study, the reliability of the index was confirmed by Cronbach's alpha coefficient of 0.97 .

The present study was approved by the Ethics Committee of Shiraz University of Medical Sciences (IR.SUMS.REC.1398.1329). The questionnaires were coded and the study data were collected anonymously. In addition, the patients were assured about the confidentiality of their data and the voluntary nature of the study. Written consent forms were also obtained from the patients.

Descriptive and inferential statistics were used to analyze the data. Spearman and Pearson correlation coefficient were used to determine the association between the variables. In addition, multiple regression analysis was used to determine the predictive roles of pain, fatigue, nausea, and vomiting in anxiety. These data were analyzed using the SPSS 26 software and $p<0.05$ was considered statistically significant.

\section{Results}

The study sample included 200 patients who had undergone HSCT. Among the patients, 112 (56\%) were male and $88(44 \%)$ were female. The participants' ages ranged from 20 to 66 years (mean $=42.78, \mathrm{SD}=$ 12.57). Besides, $67 \%$ of the participants were married and $33.5 \%$ had middle and high school degrees. Regarding the clinical characteristics, $50.7 \%$ of the participants had leukemia (acute myeloid or lymphocytic leukemia). Furthermore, $76.5 \%$ and $23.5 \%$ of the patients had undergone allogeneic and autologous transplantations, respectively. The demographic and clinical characteristics of the HSCT patients have been presented in Table 1.

The mean score of trait anxiety $(43.78, S D=9.00)$ was higher compared to state anxiety $(41.67, \mathrm{SD}=$ 9.71). Fig 1 and 2 shows the levels of state and trait anxiety. Among the participants, $53 \%$ and $63.0 \%$ had moderate state and trait anxiety levels, respectively.

The total scores of pain ranged from 0 to 10 , with a mean of 3.79 (SD $=2.79)$. Moreover, $18.6 \%, 46.1 \%$, and $35.5 \%$ of the participants had high, moderate, and low pain levels, respectively.

This study showed 165 patients $(82.5 \%)$ felt fatigue in the last week. The mean score of fatigue was $4.23(\mathrm{SD}=2.48)$, and the total scores of fatigue ranged from 0 to 9.78 . Fatigue was mild in $37.5 \%$ of participants, moderate in $42.6 \%$ and severe in $19.9 \%$ of them. 
The total scores of nausea, vomiting, and retching ranged from 0 to 31, with the mean score of 9.46 (SD = 8.50). As Table 2 shows approximately, half of the HSCT patients experienced nausea, vomiting and retching and their severity was from mild to severe. One third of them reported 1 - 4 times nausea, vomiting and retching at the last 12 hours. Moreover, 140 (70\%) of the subjects did not throw up vomiting and $44 \%$ of them felt nausea for 1 hour or less to 3 hours.

The results of correlation coefficient have been presented in Table 3. Accordingly, a significant association was found between state and trait anxiety and fatigue $(p<0.001)$. A significant association was also observed between state and trait anxiety and pain $(p<0.05)$. In addition, there were correlation between state and trait anxiety and severity of nausea, vomiting, and retching $(p<0.05)$. Significant association were also observed between state and trait anxiety and frequency of nausea, vomiting, and retching, amount of vomiting, and duration of nausea in HSCT patients $(p<0.05)$.

The results of regression analysis have been presented in Table 4. Based on this analysis fatigue, pain, severity and frequency of nausea, vomiting and retching, amount of vomiting, and times of nausea predicted $42 \%$ of the HSCT patients state anxiety variance $\left(R=0.67, R^{2}=0.45, \mathrm{ADJ} . R^{2}=0.42\right)$. The results revealed the predictor roles of pain $(p<0.001)$, fatigue $(p<0.001)$ and severity of retching in state anxiety.

This study showed above mentioned variables predicted $44 \%$ of the HSCT patients' trait anxiety variance $\left(R=0.68, R^{2}=0.47, \mathrm{ADJ} . R^{2}=0.44\right)$. Moreover, pain, fatigue, amount of vomiting, and severity of nausea, vomiting and retching predicted the HSCT patients' trait anxiety (Table 4).

\section{Discussion}

In this study, all HSCT patients showed mild to severe anxiety and $53 \%$ and $63 \%$ of the participants had moderate state and trait anxiety, respectively. It was reported that HSCT patients had moderate anxiety levels during the COVID-19 pandemic (33). On the other hand, the prevalence of anxiety was $17.53 \%$ among cancer patients during the COVID-19 pandemic (11). It should be noted that the prevalence of anxiety was higher among the HSCT patients in the present study compared to cancer patients during the COVID-19 pandemic. The HSCT patients' anxiety levels were also higher in comparison to other times than the COVID-19 pandemic. COVID-19 as infectious disease is easily transmitted to others, increases the risk of infections in HSCT patients, disturbs the transplantation process, and may lead to death. Therefore, these complications of COVID-19 might elevate the level and mean score of anxiety in these patients.

In the present study, the mean score of pain was 3.79 , and $64.7 \%$ of the participants had moderate and high levels of pain. Similarly, another study reported moderate to severe pain intensity among the patients undergoing HSCT (13). Another study also indicated that the pain burden could be potentially high in the hematology patients, especially those treated by HSCT (34). In fact, excessive bone marrow activity in the patients undergoing HSCT may lead to bone pain in these patients. 
Based on the present study findings, the mean score of fatigue was 4.23 , and $82.5 \%$ of the patients had mild to severe fatigue. Moreover, $42.6 \%$ and $19.9 \%$ of the participants reported moderate and severe fatigue levels, respectively. It was previously observed that the HSCT patients experienced high fatigue levels during their treatment period (35). In another study evaluating fatigue in allogeneic stem cell transplant recipients, patients reported $68 \%$ fatigue on the day of transplantation, $90 \%$ in the first month, and $81 \%$ on day 100 after transplantation (36).

In the present study, the mean score of nausea, vomiting and retching was 6.31. In another study, the mean score of nausea and vomiting was $7.2(S D=8.7)$ in patients undergoing chemotherapy (37). Overall, $70-80 \%$ of the patients undergoing chemotherapy experienced nausea and vomiting, which could be both acute (36\%) and delayed (59\%) (38).

The present study investigated the association between anxiety and pain, fatigue, nausea, and vomiting in the patients treated by HSCT. The results demonstrated that state and trait anxiety and fatigue had relationship with each other. In another research, patients undergoing chemotherapy with moderate to severe fatigue had higher anxiety scores and showed significantly more anxiety symptoms (39). Another research also revealed a moderate correlation between anxiety and fatigue, so that anxiety could be continuously associated with fatigue (40).

In the present study, state and trait anxiety were associated with pain. In another study also, there was a positive correlation between anxiety and pain among cancer patients (41). Anxiety was also directly related to pain in cancer patients in the COVID-19 pandemic, such a way that increase in pain might increase the anxiety level (42).

In the current study, nausea, vomiting and retching were associated with state and trait anxiety. Researchers have indicated that nausea and vomiting could be one of the main causes of anxiety in cancer patients. In other words, the presence of nausea and vomiting might lead to several mental problems, such as anxiety and depression, among these patients (19). Hence, controlling nausea and vomiting during and after the HSCT could significantly prevent or reduce the physical and psychological effects of transplantation, such as fatigue and anxiety. It could improve the patients' quality of life, as well (20).

The results of regression test in the present study demonstrated that the most important factors affecting the participants' state and trait anxiety were fatigue and pain. Moreover, severity of nausea, vomiting, and retching, duration of nausea and amount of vomiting were the predictors of trait anxiety in the study participants. A prior study disclosed that anxiety and depression were positively associated with psychological distress in HSCT patients, and fatigue might play a positive predictive role in anxiety among these patients (43). Furthermore, anxiety was significantly associated with pain in cancer patients, and pain intensity might predict anxiety in these patients (12).

Because of the current crisis in the world due to the COVID-19 pandemic, the situation has become sensitive and worrying for certain patients, such as HSCT recipients. The unknown nature of COVID-19, 
lack of studies on the disease, and lack of unique treatments and vaccines have increased the psychological burden and anxiety levels among patients, especially HSCT recipients, as well as their physicians (44). If the crisis persists, these patients will need more psychological support in addition to their main treatment (45).

One of the limitations of the present study was its cross-sectional design. Nevertheless, the study results may increase efforts to evaluate and manage common transplant complications among HSCT patients. In addition, etiological research in this field should be done in the future to determine the other factors associated with anxiety during the COVID-19 pandemic.

\section{Conclusion}

This study showed an association between state and trait anxiety and pain, fatigue, nausea, and vomiting among the HSCT patients. Considering the correlation between physical complications such as pain and fatigue and mental complications such as anxiety among the HSCT patients, healthcare workers are recommended to evaluate these patients in terms of both physical and mental problems and control and manage these complications by complementary and integrative interventions.

\section{Declarations}

\section{Funding}

This project was funded by Shiraz University of Medical Sciences, Shiraz, Iran (grant No. 20932).

\section{Conflicts of interest/Competing interests}

There are not conflicts of interest.

\section{Availability of data and material}

The data transparency was approved by FZ, NP, and MR. Data are available by MR, and NP, FZ in the form of SPSS software. Data is available on request based on the privacy and ethical limitations.

\section{Code availability}

Not applicable.

\section{Authors' contributions}

Nilofar Pasyar, Masoume Rambod, Fatemeh Zahedi, and Mani Ramzi contributed in this study. All of the authors participated in conceptualization, design, draft, read, and revised the manuscript and approval of the study and manuscript. Nilofar Pasyar, Masoume Rambod, Fatemeh Zahedi participated in data collection management. Masoume Rambod, Fatemeh Zahedi collaborated in data analysis and interpretation. 


\section{Ethics approval}

The present study was approved by the Ethics Committee of Shiraz University of Medical Sciences (IR.SUMS.REC.1398.1329).

\section{Consent to participate}

Written consent forms were obtained from the patients. The questionnaires were coded and the study data were collected anonymously. In addition, the patients were assured about the confidentiality of their data and the voluntary nature of the study.

\section{Consent for publication}

The data were published anonymously.

\section{Acknowledgements}

This project was funded by Shiraz University of Medical Sciences, Shiraz, Iran (grant No. 20932). This article was the result of the Master's thesis written by Fatemeh Zahedi and approved by Shiraz University of Medical Sciences. The authors would like to thank the healthcare providers and contributors for their participation in data collection. They would also like to appreciate all patients who participated in this study. Thanks also go to Ms. A. Keivanshekouh at the Research Improvement Center of Shiraz University of Medical Sciences for improving the use of English in the manuscript.

\section{References}

1. Sadeghi Firoozabadi V, Barani M, Bakhteyari M, MehdiZadeh M, Imani S. Effectiveness of Adjuvant Psychological Therapy on anxiety and depression of patients with hematological malignancies. Quarterly Journal of Health Psychology. 2017;6(22):51-72.

2. Smith A, Howell D, Patmore R, Jack A, Roman E. Incidence of haematological malignancy by sub-type: a report from the Haematological Malignancy Research Network. British journal of cancer. 2011;105(11):1684-92.

3. Morishita S, Kaida K, Setogawa K, Kajihara K, Ishii S, Ikegame K, et al. Safety and feasibility of physical therapy in cytopenic patients during allogeneic haematopoietic stem cell transplantation. European journal of cancer care. 2013;22(3):289-99.

4. Gemmill R, Cooke L, Williams AC, Grant M. Informal caregivers of hematopoietic cell transplant patients: a review and recommendations for interventions and research. Cancer nursing. 2011;34(6):1321.

5. El-Jawahri AR, Traeger LN, Kuzmuk K, Eusebio JR, Vandusen HB, Shin JA, et al. Quality of life and mood of patients and family caregivers during hospitalization for hematopoietic stem cell 
transplantation. Cancer. 2015;121(6):951-9.

6. Curran L, Sharpe L, Butow P. Anxiety in the context of cancer: a systematic review and development of an integrated model. Clinical psychology review. 2017;56:40-54.

7. Di Giuseppe G, Thacker N, Schechter T, Pole JD. Anxiety, depression, and mental health-related quality of life in survivors of pediatric allogeneic hematopoietic stem cell transplantation: a systematic review. Bone Marrow Transplantation. 2020:1-15.

8. Kuba K, Esser P, Mehnert A, Johansen C, Schwinn A, Schirmer L, et al. Depression and anxiety following hematopoietic stem cell transplantation: a prospective population-based study in Germany. Bone Marrow Transplantation. 2017;52(12):1651-7.

9. Lu X, Tang LV, Wang H-F, You Y, Wang Y-D, Hu Y, et al. The great challenge of managing recipients of hematopoietic stem cell transplantation combined with COVID-19. Bone Marrow Transplantation. 2020:1-5.

10. Pitman A, Suleman S, Hyde N, Hodgkiss A. Depression and anxiety in patients with cancer. Bmj. 2018;361.

11. Yu H, Zhou Z, Mo Q, Zhou X, Liu Y, Feng S. Prevalence of Anxiety and Depression Among Cancer Patients During the COVID-19 Pandemic: a Systematic Review and Meta-analysis. 2020.

12. Aryaie M, Bagheri D, Ozouni-Davaji RB, Mostafshar S, Bolukat E, Khodabakhshi R. Association of anxiety, depression, and body image disorder with pain-related disability in post-mastectomy breast cancer patients. Journal of Clinical Basic Research. 2017;1(4):26-30.

13. Oh HJ, Hong SY, Jeong YM, Choi KS, Lee E, Lee E, et al. Drug use evaluation of opioid analgesics in pain management among patients with hematopoietic stem cell transplantation. Blood research. 2020;55(3):151.

14. de Sousa GCC, das Mercês NNA, da Silva LAGP, Macedo A. Pain management in children and teenagers during the hematopoietic stem cell post-transplant period: an integrative review. Enfermería Global. 2019;18(1):567-81.

15. Brooks SK, Webster RK, Smith LE, Woodland L, Wessely S, Greenberg N, et al. The psychological impact of quarantine and how to reduce it: rapid review of the evidence. The Lancet Haematology. 2020;395:912-20.

16. Costanzo ES, Knight JM, Coe CL, Hematti P, Juckett MB. Prevalence and Biobehavioral Predictors of Early and Long-Term Fatigue Following Hematopoietic Stem Cell Transplantation. Biology of Blood Marrow Transplantation. 2020;26(3):8-74. 
17. Amonoo HL, Fenech A, Greer JA, Temel JS, Huffman JC, El-Jawahri A. Does Desire to Pursue Pleasurable Activities Matter? The Impact of Pre-transplant Anhedonia on Quality of Life and Fatigue in Hematopoietic Stem Cell Transplantation. Biology of Blood Marrow Transplantation. 2020;26:1477-81.

18. Boberg E, Kadri N, Winterling J, Davies LC, Björklund A, Msghina M, et al. Mental fatigue after allogeneic hematopoietic stem cell transplantation is associated with cognitive dysfunction, but not central nervous system inflammation. Haematologica. 2020;105(6):e310.

19. So WK, Marsh G, Ling W, Leung F, Lo JC, Yeung M, et al. Anxiety, depression and quality of life among Chinese breast cancer patients during adjuvant therapy. European journal of oncology nursing. 2010;14(1):17-22.

20. Flank J, Sparavalo J, Hagen L, Stuhler R, Chong D, Courtney S, et al. The burden of chemotherapy-induced nausea and vomiting in children receiving hematopoietic stem cell transplantation conditioning: a prospective study. Bone Marrow Transplantation. 2017;52(9):1294-9.

21. Jacobse J, Mensink H, van der Stoep MEC, Kollen WJ, Bresters D, Bredius RG. Long-term aprepitant for nausea and vomiting associated with gastroparesis in hematopoietic stem cell transplantation. Bone marrow transplantation. 2018;53(10):1372-4.

22. Haverman T, Raber-Durlacher J, Rademacher W, Vokurka S, Epstein J, Huisman C, et al. Oral complications in hematopoietic stem cell recipients: the role of inflammation. Mediators of inflammation. $2014 ; 2014$.

23. Baydoun M, Barton DL. Complementary therapies for fatigue after hematopoietic stem cell transplantation: an integrative review. Bone marrow transplantation. 2018;53(5):556-64.

24. Di Renzo N, Musso M, Scimè R, Cupri A, Perrone T, De Risi C, et al. Efficacy and safety of multiple doses of NEPA without dexamethasone in preventing nausea and vomiting induced by multiple-day and high-dose chemotherapy in patients with non-Hodgkin's lymphoma undergoing autologous hematopoietic stem cell transplantation: a phase Ila, multicenter study. Bone Marrow Transplantation. 2020;22:2114-20.

25. Speilberger C, Gorsuch R, Lushene R. State-trait anxiety inventory. Palo Alto. CA: Consulting Psychologists Press; 1970.

26. Pasyar N, Rambod M, Kahkhaee FR. The effect of foot massage on pain intensity and anxiety in patients having undergone a tibial shaft fracture surgery: a randomized clinical trial. Journal of orthopaedic trauma. 2018;32(12):482-6.

27. Phan NQ, Blome C, Fritz F, Gerss J, Reich A, Ebata T, et al. Assessment of pruritus intensity: prospective study on validity and reliability of the visual analogue scale, numerical rating scale and verbal rating scale in 471 patients with chronic pruritus. Acta dermato-venereologica. 2012;92(5):502-7. 
28. Rambod M, Sharif F, Pourali-Mohammadi N, Pasyar N, Rafii F. Evaluation of the effect of Benson's relaxation technique on pain and quality of life of haemodialysis patients: A randomized controlled trial. International journal of nursing studies. 2014;51(7):964-73.

29. Okuyama T, Wang XS, Akechi T, Mendoza TR, Hosaka T, Cleeland CS, et al. Validation study of the Japanese version of the brief fatigue inventory. Journal of pain symptom management. 2003;25(2):106-17.

30. Haghighi S. The effect of exercise in fatigue intensity in cancer patients under chemotherapy in Shafa hospital: Faculty of nursing and midwifery. Ahvaz Jondishapur University of Medical Sciences. 2003.

31. Molassiotis A, Coventry PA, Stricker CT, Clements C, Eaby B, Velders L, et al. Validation and psychometric assessment of a short clinical scale to measure chemotherapy-induced nausea and vomiting: the MASCC antiemesis tool. Journal of pain symptom management. 2007;34(2):148-59.

32. Moradian S, Shahidsales S, Ghavam Nasiri M, Pilling M, Molassiotis A, Walshe C. Translation and psychometric assessment of the $\mathrm{P}$ ersian version of the $\mathrm{R}$ hodes I ndex of $\mathrm{N}$ ausea, $\mathrm{V}$ omiting and $\mathrm{R}$ etching (INVR) scale for the assessment of chemotherapy-induced nausea and vomiting. European journal of cancer care. 2014;23(6):811-8.

33. Kabak VY, Uysal SA, Duger T. Screening Supportive Care Needs, Compliance to Exercise Program, Quality of Life, and Anxiety Level During the COVID-19 Pandemic in Individuals Treated with Hematopoietic Stem Cell Transplantation. 2020.

34. Niscola P, Romani C, Cartoni C, Cupelli L, Piccioni D, Dentamaro T, et al. Epidemiology of pain in hospital haematological setting: an Italian survey. Leukemia Research. 2008;1(32):197-8.

35. Jafari H, Jannati Y, Nesheli HM, Hassanpour S. Effects of nonpharmacological interventions on reducing fatigue after hematopoietic stem cell transplantation. Journal of research in medical sciences: the official journal of Isfahan University of Medical Sciences. 2017;22(13).

36. Bevans MF, Mitchell SA, Marden S. The symptom experience in the first 100 days following allogeneic hematopoietic stem cell transplantation (HSCT). Supportive Care in Cancer. 2008;16(11):124354.

37. Soleimani M, Shakib-Khankandi A, Ghahremanfard F, Mirmohammadkhani M. Arterial oxygen saturation and severity of nausea and vomiting during chemotherapy: A pilot study. Tehran University Medical Journal. 2015:698-705.

38. Craver C, Gayle J, Balu S, Buchner D. Clinical and economic burden of chemotherapy-induced nausea and vomiting among patients with cancer in a hospital outpatient setting in the United States. Journal of Medical Economics. 2011;14(1):87-98. 
39. Poort H, Jacobs JM, Pirl WF, Temel JS, Greer JA. Fatigue in patients on oral targeted or chemotherapy for cancer and associations with anxiety, depression, and quality of life. Palliative supportive care. 2020;18(2):141-7.

40. Brown LF, Kroenke K. Cancer-related fatigue and its associations with depression and anxiety: a systematic review. Psychosomatics. 2009;50(5):440-7.

41. Lee KE, Lee YE. The relationship between the spiritual health, anxiety and pain in hospitalized cancer patients. The Korean Journal of Hospice Palliative Care. 2015;18(1):25-34.

42. Letaief-Ksontini F, Zenzri Y, Yahyaoui Y, Gabsi A, Mokrani A, Meddeb K. 1573P Anxiety and depression in cancer patients during the COVID-19 pandemic: A single-centre study. Annals of Oncology. 2020;31:S957.

43. Warchala A, Krupka-Matuszczyk I, Krysta K. Anxiety and depression in patients with acute leukaemia treated with hematopoietic stem cell transplantation. Psychiatria Danubina. 2019;31(Suppl 3):231-6.

44. Sahu KK, Siddiqui AD, Cerny J. COVID-19 pandemic and impact on hematopoietic stem cell transplantation. Bone Marrow Transplantation. 2020;55:2193-5.

45. Hennessy M, Linehan A, Cowzer D, Coyne Z, Fitzpatrick O, Dhonaill RN, et al. Chemotherapy in the COVID-19 era: The patient's perception. Annals of Oncology. 2020;31:957.

\section{Tables}

Table 1. Demographic and clinical characteristics of the HSCT patients $(N=200)$ 


\begin{tabular}{|ll|}
\hline Variable & $\mathbf{n}(\%)$ \\
\hline Gender & \\
Male & $112(56.0)$ \\
Female & $88(44.0)$ \\
\hline Education levels & \\
illiterate & $15(7.5)$ \\
Primary school & $51(25.5)$ \\
Secondary and high school & $67(33.5)$ \\
Academic & $67(33.5)$ \\
\hline Marital status & \\
Single & $52(26.0)$ \\
Married & $134(67.0)$ \\
Divorced & $10(5.0)$ \\
Widowed & $4(2.0)$ \\
\hline Disease diagnosis & \\
Multiple Myeloma & $78(39.6)$ \\
Acute Myeloid leukemia & $41(20.8)$ \\
Acute lymphocytic leukemia & $47(23.9)$ \\
Lymphoma & $25(12.7)$ \\
Aplastic anemia & $6(3.0)$ \\
\hline Type of HSCT & $75(37.5)$ \\
Autologous & $125(62.5)$ \\
Allogeneic & \\
\hline Reching in the HScT patents & \\
\hline
\end{tabular}

Table 2. Nausea, Vomiting and Retching in the HSCT patients the last12 hours 


\begin{tabular}{|c|c|c|c|}
\hline Variables & Nausea & Vomiting & Retching \\
\hline \multicolumn{4}{|l|}{ Severity } \\
\hline No & $94(47.0)$ & $119(59.5)$ & 115 (57.5) \\
\hline Mild & $48(24.0)$ & $36(18.0)$ & $41(20.5)$ \\
\hline Moderate & $36(18.0)$ & $33(16.5)$ & $27(13.5)$ \\
\hline Great & $17(8.5)$ & $8(4.0)$ & $11(5.5)$ \\
\hline Severe & $5(2.5)$ & $4(2.0)$ & $6(3.0)$ \\
\hline \multicolumn{4}{|l|}{ Frequency ${ }^{a}$} \\
\hline No & $102(51.0)$ & $139(69.5)$ & $108(54.0)$ \\
\hline $1-2$ & $46(23.0)$ & $34(17.0)$ & $47(23.5)$ \\
\hline $3-4$ & $29(14.5)$ & $12(6.0)$ & $18(9.0)$ \\
\hline $5-6$ & $9(4.5)$ & $7(3.5)$ & $18(9.0)$ \\
\hline 7 or more & $14(7.0)$ & $8(4.0)$ & $9(4.5)$ \\
\hline \multicolumn{4}{|l|}{ Amount } \\
\hline Very large ${ }^{b}$ & & $5(2.5)$ & \\
\hline Large $^{c}$ & & $7(3.5)$ & - \\
\hline Moderate $d$ & & $7(3.5)$ & \\
\hline & & $41(20.5)$ & \\
\hline Small ${ }^{e}$ & & $140(70.0)$ & \\
\hline I did not throw up & & & \\
\hline \multicolumn{4}{|l|}{ How much times } \\
\hline Not at all & $88(44.0)$ & & \\
\hline 1 hour or less & $55(27.5)$ & --_- & - \\
\hline $2-3$ hours & $33(16.5)$ & & \\
\hline 4-6 hours & $7(3.5)$ & & \\
\hline More than 6 hours & $17(8.5)$ & & \\
\hline
\end{tabular}

${ }^{a}$ times, ${ }^{b}$ Very large (3 cups or more), ${ }^{c}$ large (2-3 cups), ${ }^{d}$ moderate (1/2-2 cups), ${ }^{e}$ small (up to $1 / 2$ cup)

Table 3. The association between state and trait anxiety and fatigue, pain, nausea, vomiting and retching in HSCT patients 


\begin{tabular}{|lll|}
\hline Variables & State anxiety & Trait anxiety \\
\hline Fatigue & $r=0.61, P<0.001$ & $r=0.58, p<0.001$ \\
\hline Pain & $r=0.54, p<0.001$ & $r=0.56, p<0.001$ \\
\hline Severity of nausea & $r=0.33, p<0.001$ & $r=0.26, p<0.001$ \\
\hline Severity of vomiting & $r=0.31, p<0.001$ & $r=0.23, p=0.001$ \\
\hline Severity of retching & $r=0.41, p<0.001$ & $r=0.33, p<0.001$ \\
\hline Frequency of nausea & $r=0.29, p<0.001$ & $r=0.18, p=0.008$ \\
\hline Frequency of vomiting & $r=0.28, p<0.001$ & $r=0.25, p<0.001$ \\
\hline Frequency of retching & $r=0.34, p<0.001$ & $r=0.27, p<0.001$ \\
\hline Amount of vomiting & $r=0.27, p<0.001$ & $r=0.22, p=0.001$ \\
\hline Duration of nausea & $r=0.26, p<0.001$ & $r=0.22, p=0.002$ \\
\hline
\end{tabular}

Table 4. The results of regression analysis for determining the predictive roles of pain, fatigue, nausea, and vomiting in the HSCT patients' state anxiety $(n=200)$ 


\begin{tabular}{|c|c|c|c|c|c|c|}
\hline & \multicolumn{2}{|c|}{$\begin{array}{l}\text { Unstandardized } \\
\text { Coefficients }\end{array}$} & \multirow{2}{*}{$\begin{array}{l}\text { Standardized } \\
\text { Coefficients } \\
\text { Beta }\end{array}$} & \multirow[t]{2}{*}{$t$} & \multirow[t]{2}{*}{$\begin{array}{l}\mathrm{P} \text { - } \\
\text { value }\end{array}$} & \multirow[t]{2}{*}{$95 \% \mathrm{Cl}^{\mathrm{a}}$} \\
\hline & B & Std. Error & & & & \\
\hline 1 (constant) & 31.27 & 1.10 & & 28.27 & $<.001$ & $\begin{array}{l}29.08 \\
33.45\end{array}$ \\
\hline Fatigue & 1.71 & 0.28 & 0.43 & 6.06 & $<.001$ & $1.15,2.27$ \\
\hline Pain & 0.71 & 0.25 & 0.20 & 2.83 & 0.005 & $0.21,1.21$ \\
\hline Severity of nausea & 1.39 & 1.06 & 0.15 & 1.31 & 0.19 & $\begin{array}{l}-0.69 \\
3.49\end{array}$ \\
\hline $\begin{array}{l}\text { Severity of } \\
\text { vomiting }\end{array}$ & 1.11 & - $^{1.31}$ & -0.11 & -0.85 & 0.39 & $\begin{array}{l}-3.71 \\
1.47\end{array}$ \\
\hline $\begin{array}{l}\text { Severity of } \\
\text { retching }\end{array}$ & 2.69 & 1.24 & 0.29 & 2.16 & 0.03 & $0.23,5.14$ \\
\hline $\begin{array}{l}\text { Frequency of } \\
\text { nausea }\end{array}$ & 0.87 & • 0.83 & -0.10 & -1.49 & 0.29 & $\begin{array}{l}-2.52 \\
0.77\end{array}$ \\
\hline $\begin{array}{l}\text { Frequency of } \\
\text { vomiting }\end{array}$ & 0.60 & 0.99 & 0.06 & 0.60 & 0.54 & $\begin{array}{l}-1.36 \\
2.56\end{array}$ \\
\hline $\begin{array}{l}\text { Frequency of } \\
\text { retching }\end{array}$ & 0.05 & 0.80 & 0.007 & 0.07 & 0.94 & $\begin{array}{l}-1.53 \\
1.64\end{array}$ \\
\hline $\begin{array}{l}\text { Amount of } \\
\text { vomiting }\end{array}$ & 1.46 &.$^{0.98}$ & -0.13 & -1.49 & 0.13 & $\begin{array}{l}-3.41 \\
0.47\end{array}$ \\
\hline $\begin{array}{l}\text { Duration of } \\
\text { nausea }\end{array}$ & 0.97 & . $^{0.78}$ & -0.12 & -1.23 & 0.21 & $\begin{array}{l}-2.52 \\
0.58\end{array}$ \\
\hline
\end{tabular}

a $95.0 \%$ confidence interval for $B$

Table 5: Multiple linear regression analysis predicting HSCT patients' trait anxiety $(n=200)$ 


$\begin{array}{lllll}95 \% \mathrm{Cl}^{a} & \begin{array}{l}\text { P- } \\ \text { value }\end{array} & t & \begin{array}{l}\text { Standardized } \\ \text { Coefficients }\end{array} & \begin{array}{l}\text { Unstandardized } \\ \text { Coefficients }\end{array}\end{array}$

Factors

\begin{tabular}{|c|c|c|c|c|c|c|}
\hline & & & Beta & Std. Error & B & \\
\hline $\begin{array}{l}32.42 \\
36.41\end{array}$ & $<.001$ & 34.05 & & 1.01 & 34.42 & 1 (constant) \\
\hline $0.74,1.76$ & $<.001$ & 4.85 & 0.34 & 0.25 & 1.25 & Fatigue \\
\hline $0.32,1.23$ & 0.001 & 3.35 & 0.24 & 0.23 & 0.77 & Pain \\
\hline $1.16,4.99$ & 0.002 & 3.17 & 0.37 & 0.97 & 3.08 & Severity of nausea \\
\hline $\begin{array}{l}-4.92 \\
-0.18\end{array}$ & 0.03 & -2.12 & -0.28 & 1.20 & - 2.65 & $\begin{array}{l}\text { Severity of } \\
\text { vomiting }\end{array}$ \\
\hline $0.41,4.89$ & 0.02 & 2.33 & 0.31 & 1.13 & 2.65 & $\begin{array}{l}\text { Severity of } \\
\text { retching }\end{array}$ \\
\hline $\begin{array}{l}-2.36 \\
0.66\end{array}$ & 0.27 & -1.10 & -0.11 & 0.76 & - 0.84 & $\begin{array}{l}\text { Frequency of } \\
\text { nausea }\end{array}$ \\
\hline $\begin{array}{l}-0.35 \\
3.23\end{array}$ & 0.11 & 1.58 & 0.16 & 0.90 & 1.44 & $\begin{array}{l}\text { Frequency of } \\
\text { vomiting }\end{array}$ \\
\hline $\begin{array}{l}-1.25 \\
1.65\end{array}$ & 0.78 & 0.27 & 0.02 & 0.73 & 0.20 & $\begin{array}{l}\text { Frequency of } \\
\text { retching }\end{array}$ \\
\hline $\begin{array}{l}-3.80,- \\
0.25\end{array}$ & 0.02 & -2.25 & -0.20 & 0.90 & - 2.03 & $\begin{array}{l}\text { Amount of } \\
\text { vomiting }\end{array}$ \\
\hline $0.41,4.89$ & 0.02 & 2.33 & -0.16 & 0.71 & - 1.19 & $\begin{array}{l}\text { duration of } \\
\text { nausea }\end{array}$ \\
\hline
\end{tabular}

a $95.0 \%$ confidence interval for B

\section{Figures}




\section{State Anxiety}

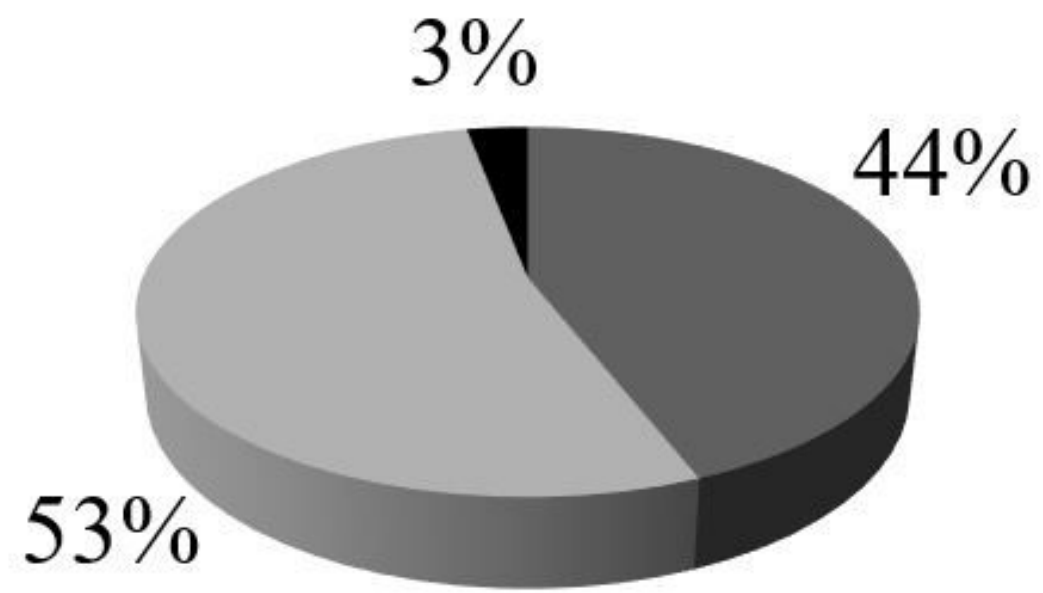

- Mild

Moderate

- Severe

Figure 1

The HSCT patients' state anxiety levels

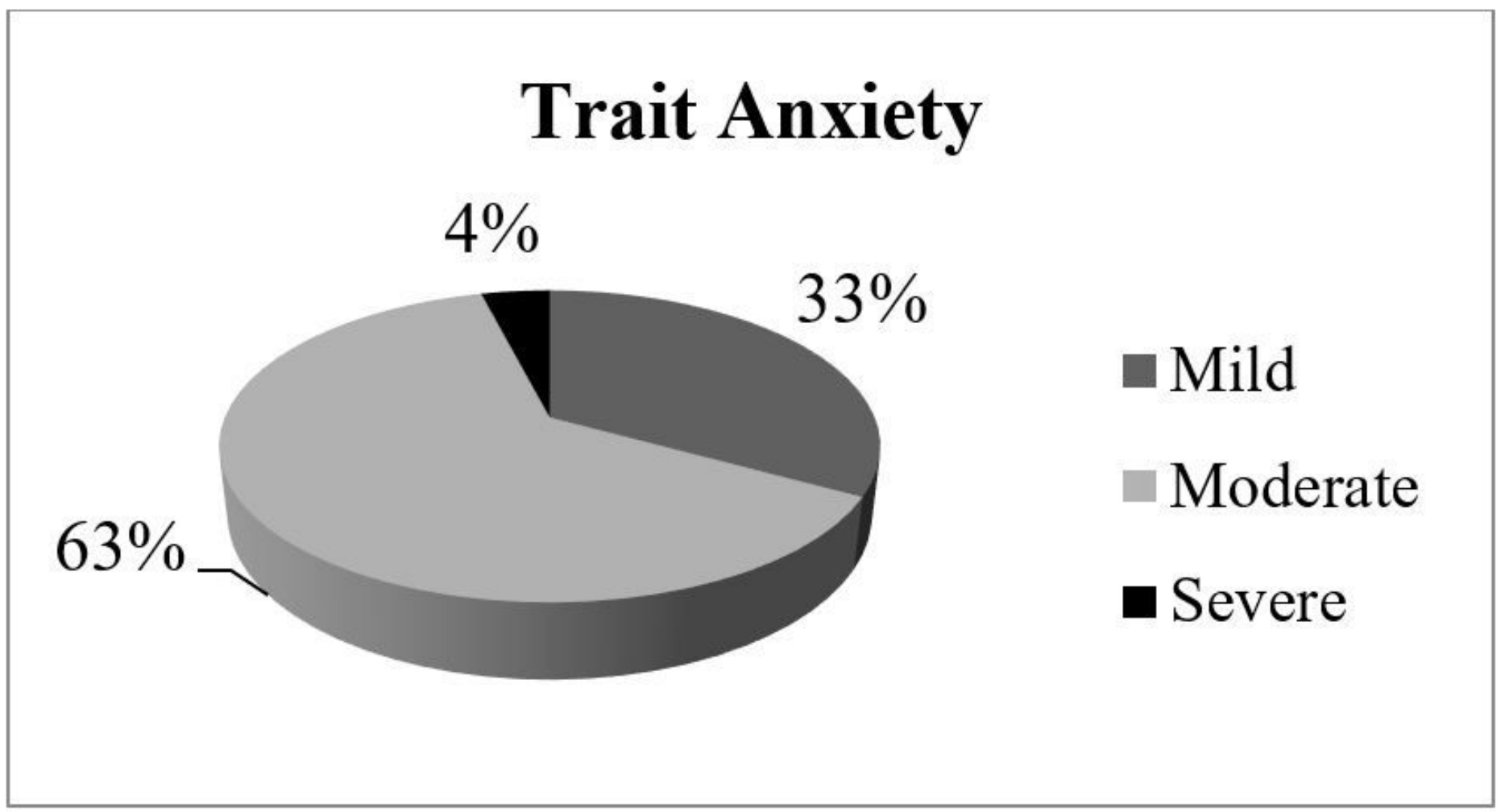

Figure 2 
The HSCT patients' trait anxiety levels

\section{Supplementary Files}

This is a list of supplementary files associated with this preprint. Click to download.

- coidisclosureRambod.pdf

- coidisclosure1.Pasyar.pdf

- coidisclosure.Ramzi.pdf

- coidisclosure.zaedi.pdf 